\title{
A Scanning Electron Microscope Analysis of Sealing Potential and Marginal Adaptation of Different Root Canal Sealers to Dentin: An In Vitro study
}

\author{
Gaurav Patri ${ }^{1}$, Pratik Agrawal ${ }^{2}$, Nanjegowda Anushree ${ }^{3}$, Suraj Arora ${ }^{4}$, Jimly J Kunjappu ${ }^{5}$, Shaheen V Shamsuddin ${ }^{6}$
}

\begin{abstract}
Aim: The present study aimed to evaluate the sealing potential and marginal adaptation of different root canal sealers to dentin.

Materials and methods: A total of sixty human lower premolars of the permanent dentition that were extracted were used for this study. The visible debris and calculus were removed from the extracted teeth ultrasonically and were kept for 2 hours in $2.5 \%$ sodium hypochlorite and stored in normal saline till next use. A low-speed diamond disc was used to section all the teeth samples at the cementoenamel junction. Later, cleaning and shaping of the canals was done. Based on the sealer used, the samples (each group consisting of 20 samples) were divided randomly into three groups: group I—bioceramic sealer, group II—resin-based sealer, group III—MTA-based sealer. All split samples were visualized under scanning electron microscope (SEM) at apical and coronal thirds of root canal, the marginal gap at root dentin and sealer interface were assessed. Results: The highest marginal adaptation $(5.60 \pm 0.12)$ was demonstrated by EndoSequence BC sealer, followed immediately by ProRoot MTA sealer ( $4.48 \pm 0.12)$ and EndoREZ sealer $(2.10 \pm 0.54)$. A statistically significant difference $(p=0.001)$ was seen between the EndoSequence BC and ProRoot MTA sealer for apical and coronal marginal adaptation. Also, a statistically significant difference $(p<0.05)$ was found between EndoSequence BC sealer vs EndoREZ sealer at coronal and EndoSequence BC sealer vs EndoREZ sealer and EndoREZ sealer vs ProRoot MTA sealer at apical third.
\end{abstract}

Conclusion: The present study concluded that significant and better sealing ability and marginal adaptation was demonstrated by EndoSequence BC (bioceramic sealer) when compared to ProRoot MTA sealer (MTA-based sealer) and EndoREZ sealer (resin-based sealer).

Clinical significance: Numerous endodontic sealers enter the market with various factors to attain acceptable seal. According to current study bioceramic sealer, is the appropriate sealer that hermetically seals all the margins.

Keywords: Dentinal tubule penetration, Marginal adaptation, Root canal sealer, Scanning electron microscope.

The Journal of Contemporary Dental Practice (2020): 10.5005/jp-journals-10024-2733

\section{INTRODUCTION}

Restorations are intended for carious teeth, crowns are made to preserve damaged teeth, and endodontic treatment aims at treatment of pulpally involved teeth. The optimal endodontic obturation technique should essentially offer a dimensionally stable and tight apical seal without fluid leakage so as to avoid any communication between the root canals and the adjoining periapical tissues via the apical foramen. The conventional endodontic treatment is reported to be successful in $79-96 \%$ of all the cases. ${ }^{1}$

The root canals that are not obturated completely contribute to $58 \%$ of endodontic failures. The causes for incomplete obturation may be inappropriate obturation technique or incomplete instrumentation. The root canal sealers that are used during obturation technique should function as a lubricant; seal the minuscule gap between the gutta-percha and the canal wall, and support the seating of gutta-percha cones. The root canal sealers should also seal the patent lateral and accessory canals, bury the bacteria within the tubules of dentin and permit repair of the damaged periapical tissue. ${ }^{2}$

Previously too much unnecessary emphasis has been placed on whether the filling has reached the radiographic apex or not. Nevertheless, enduring success of root canal treatment (RCT) relies on three-dimensional obturation of root canal. The chief factors responsible for successful RCT are lack of apical and coronal micro leakage, extent of penetration of sealers in to the tubules and sealing off the minute gap between canal wall and sealers. In order
${ }^{1,2}$ Department of Conservative Dentistry and Endodontics, Kalinga Institute of Dental Sciences, KIIT Deemed to be University, Bhubaneswar, Odisha, India

${ }^{3}$ Department of Oral and Maxillofacial Surgery, Subbaiah Institute of Dental Sciences, Shivamogga, Karnataka, India

${ }^{4}$ Department of Restorative Dental Sciences, College of Dentistry, King Khalid University, Abha, Kingdom of Saudi Arabia

${ }^{5}$ Department of Periodontics, College of Dentistry, King Khalid University, Abha, Kingdom of Saudi Arabia

${ }^{6}$ Department of Pediatric Dentistry and Orthodontics, College of Dentistry, Division of Orthodontics, King Khalid University, Abha, Kingdom of Saudi Arabia

Corresponding Author: Gaurav Patri, Department of Conservative Dentistry and Endodontics, Kalinga Institute of Dental Sciences, KIIT Deemed to be University, Bhubaneswar, Odisha, India, Phone: +91 9437962964, e-mail: patrigaurav@gmail.com

How to cite this article: Patri G, Agrawal P, Anushree N, et al. A Scanning Electron Microscope Analysis of Sealing Potential and Marginal Adaptation of Different Root Canal Sealers to Dentin: An In Vitro study. J Contemp Dent Pract 2020;21(1):73-77.

Source of support: Nil

Conflict of interest: None

to minimize micro leakage, the adaptations between root canal wall and sealer has to be excellent which would further increase the root canal breaking strength meaningfully. ${ }^{3}$ 
Recently in root canal sealers technology, there have been an improvement in the formulation. The traditional zinc oxide eugenol sealers have been replaced with MTA-based, resin-based, bioceramic-based and silicone-based sealers. Mainly, bioceramicbased sealers are getting popularity because of their chemical stability, alkaline $\mathrm{pH}$ within the biological environment, more biocompatible and lack of shrinkage. ${ }^{4}$

Furthermore, deep penetration of the sealer in to the tubules advances the fracture resistance of root canal. Thus, an ultimate root canal sealer should penetrate up to the entire depth of dentinal tubules and adapt completely with the root canal walls. ${ }^{5}$ Therefore, this study was undertaken to compare the better sealing ability and marginal adaptation of various root canal sealers to dentin.

\section{Materials and Methods}

This in vitro study was conducted in the Department of Conservative Dentistry and Endodontics, Kalinga Institute of Dental Sciences, Bhubaneswar.

A total of 60 human lower premolars of the permanent dentition that were extracted for orthodontic purpose were used for this study. The extracted teeth were excluded if they had severe curvatures, resorption, incomplete apex formation and/or craze lines. The visible debris and calculus were removed from the extracted teeth ultrasonically and were kept for two hours in $2.5 \%$ sodium hypochlorite as extracted teeth must be decontaminated to prevent spread of infection. And then they were stored in normal saline till next use. A low-speed diamond disc was used to section all the teeth samples at the cementoenamel junction. A K-file \#10 (Dentsply Meillefer, OK, USA) was introduced into the root canal to the length until its tip was visible at the tooth apex. In order to attain the working length during the root canal preparation, this length was reduced by $1 \mathrm{~mm}$. A step-back system was followed with hand K-files starting with an initial K-file \#25 to master apical file \#40. The shaping was continued up to K-file \#80. The paper points (DiaDent, Seoul, South Korea) were used to dry the root canals.

Based on the sealer used, the samples (each group consisting of 20 samples) were divided randomly into three groups:

\section{Group I-Bioceramic Sealer [EndoSequence BC (Brasseler, Savannah, GA, USA)]}

A syringe tip was used to place the premixed bioceramic sealer up to $2 / 3$ rd of the root canal. After dipping the gutta-percha cone in the sealer, it was inserted in the root canal with slow up and down motion until it reaches the full working length. The cone was later seared off at the level of the orifices.

\section{Group II-Resin-based Sealer [EndoREZ (Ultadent Products. Inc)]}

Prior to the placement of sealer, the canal has to be moist and not dried. A skin syringe with a mixing tip at the back is used to express the EndoREZ sealer. Gutta-percha point smeared with sealer was inserted up to the working length. The gutta-percha cone was then seared off at the orifice level.

\section{Group III-MTA-based Sealer [ProRoot MTA (Dentsply, Tulsa, OK, USA)]}

A self-mixing tip attached to a syringe was used to mix the sealer. The sealer was then applied to root canal space ProTaper. The gutta-percha point layered with sealer was introduced up to the working length. The gutta-percha cone was then seared off at the orifice level.

\section{Evaluation of Marginal Adaptation Using Scanning Electron Microscopy}

The obturated teeth were stored for 1 week at 100\% humidity and a temperature of $37^{\circ} \mathrm{C}$. The teeth samples were cut vertically using a hard tissue microtome so as to minimize the chances of formation of crack in both the tooth structure and the material. The marginal gap at root dentin and sealer interface was evaluated at apical and coronal third of root canal under SEM.

All the samples were viewed under SEM after being mounted on an aluminum stub which was sputter coated with gold. A single examiner measured the highest gap width as the highest distance between root canal dentin and obturated material with a magnification of $\times 2,000$ (Figs 1 and 2).

\section{Statistical Analysis}

A Statistical Package for Social Sciences (SPSS) of version 20 (SPSS Inc. Chicago, IL, USA) was applied to analyze data. The significant difference was evaluated using Kruskal-Wallis tests and MannWhitney $U$ test. A $p$ value of $<0.05$ was considered to be statistically significant.

\section{Results}

The mean and standard deviation of three different sealers was shown in Table 1. The highest marginal adaptation (5.60 \pm 0.12$)$ was demonstrated by EndoSequence BC sealer, followed next by ProRoot MTA sealer ( $4.48 \pm 0.12)$ and EndoREZ sealer $(2.10 \pm 0.54)$

The difference between the apical and coronal marginal adaptation was statistically significant $(p=0.001)$ with EndoSequence $B C$ and ProRoot MTA sealer respectively. However, EndoREZ sealer did not show any difference between the apical and coronal marginal adaptation that was significant (Table 2).

At Table 3, coronal third comparison was done using a Mann Whitney $U$ test. EndoSequence $B C$ sealer vs EndoREZ sealer showed statistically significant difference $(p<0.05)$.

As shown by Table 4, the inter group comparison for the apical third was done. A statistically significant difference $(p<0.05)$ was found for EndoSequence BC sealer vs EndoREZ sealer and EndoREZ sealer vs ProRoot MTA sealer.

The inference of the present study indicates that the EndoSequence BC (bioceramic sealer) significantly has better sealing ability and marginal adaptation followed by ProRoot MTA sealer (MTA-based sealer) and EndoREZ sealer (resin-based sealer).

\section{Discussion}

The chief objective of obturation technique is to deliver a seal in all three dimensions, thus avoiding the recurrence of infection in root canals and preserve the periapical tissues in a healthy condition. The gold standard in RCTs is obturation of root canals with root canal sealers and gutta-percha. Despite several benefits, root canal sealers have some demerits such as, lack of ability to bond completely with dentin that lines the root canals. On setting, the sealer may also tweak away from the gutta-percha due to its hydrophobic nature. ${ }^{6}$

Previously, several trials have evaluated the sealing ability of the root canal sealers by assessing the extent of microleakage. Yet, there have been disparities in these trials ${ }^{7}$ and the results 

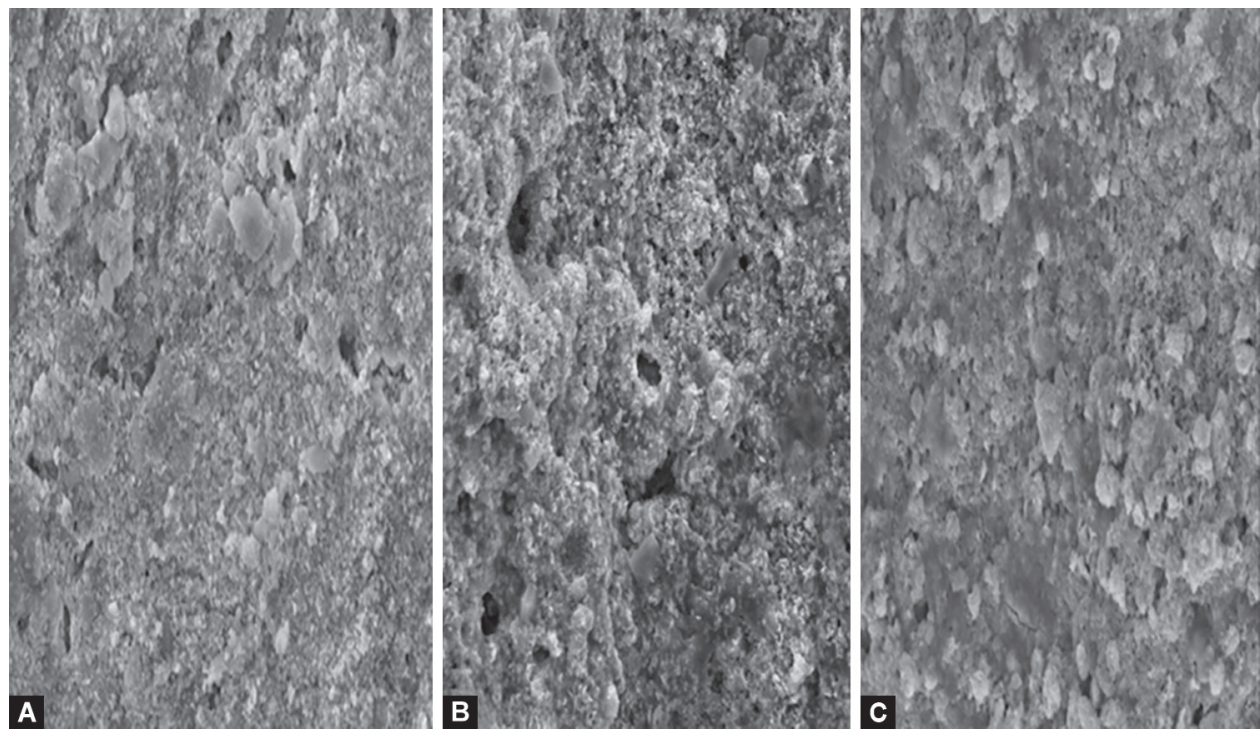

Figs $1 \mathrm{~A}$ to C: Scanning electron microscope images of: (A) EndoSequence BC sealer; (B) EndoREZ sealer; (C) ProRoot MTA sealer at coronal third
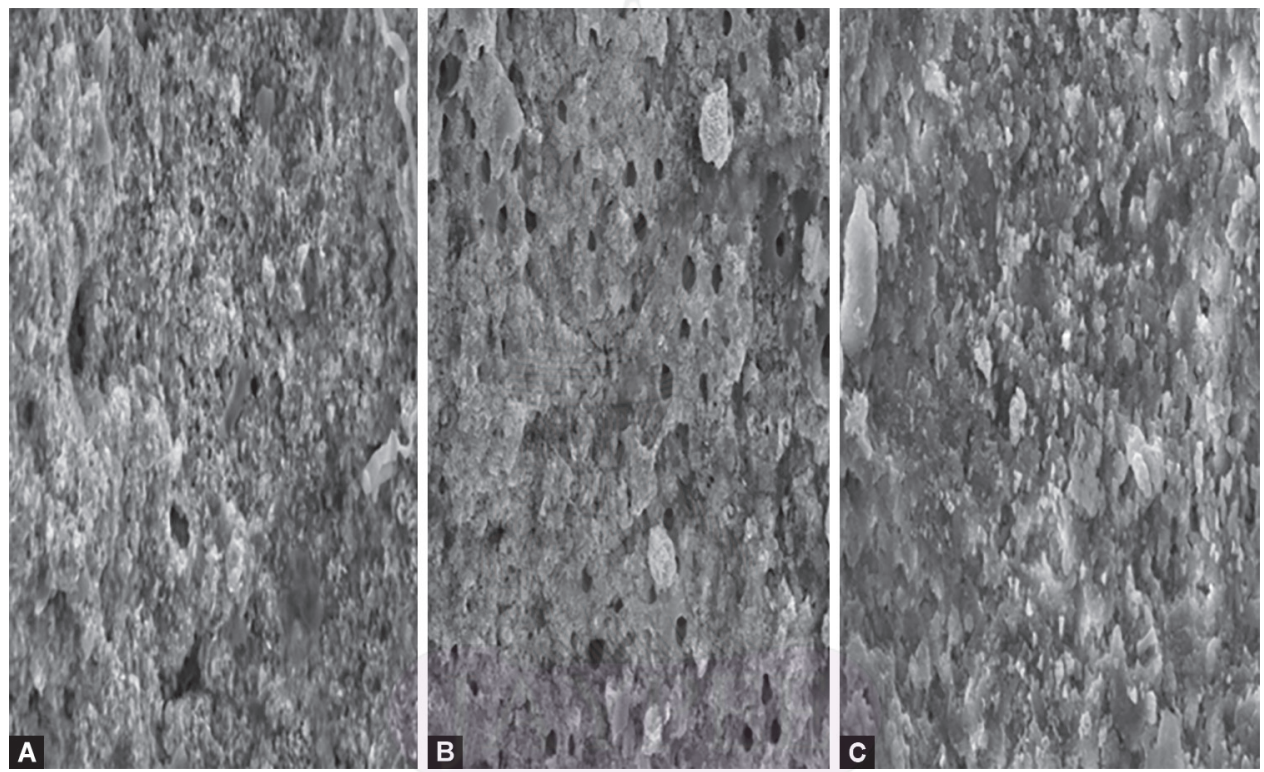

Figs 2A to C: Scanning electron microscope images of: (A) EndoSequence BC sealer; (B) EndoREZ sealer; (C) ProRoot MTA sealer at apical third

Table 1: Statistical analysis of mean and standard deviation of three different sealer's marginal adaptations

\begin{tabular}{lll}
\hline Sealer's group & $n$ & Mean $\pm(S D)$ \\
\hline Group I: EndoSequence BC sealer & 20 & $5.60 \pm 0.12$ \\
Group II: EndoREZ sealer & 20 & $2.10 \pm 0.54$ \\
Group III: ProRoot MTA sealer & 20 & $4.48 \pm 0.12$ \\
\hline
\end{tabular}

Table 2: Sealing potential and marginal adaptation of different sealers at coronal and apical levels

\begin{tabular}{lllll}
\hline Type of sealer & $\begin{array}{l}\text { Coronal } \\
\text { (mean } \pm S D)\end{array}$ & $\begin{array}{l}\text { Apical } \\
\text { (mean } \pm S D)\end{array}$ & $\begin{array}{l}\text { KANOVA } \\
\text { value }\end{array}$ & p value \\
\hline $\begin{array}{l}\text { EndoSequence } \\
\text { BC sealer }\end{array}$ & $2.30 \pm 0.01$ & $3.30 \pm 0.11$ & 26.00 & 0.001 \\
$\begin{array}{l}\text { EndoREZ sealer } \\
\begin{array}{l}\text { ProRoot MTA } \\
\text { sealer }\end{array}\end{array}$ & $0.96 \pm 0.04$ & $1.14 \pm 0.50$ & 24.80 & 0.084 \\
\hline
\end{tabular}

Table 3: Intergroup comparison at coronal third

\begin{tabular}{llll}
\hline Inter groups & Mean rank & Mann-Whitney U test & p value \\
\hline $\begin{array}{l}\text { EndoSequence BC sealer } \\
\text { vs EndoREZ sealer }\end{array}$ & $22.80-6.20$ & 40.20 & 0.001 \\
$\begin{array}{l}\text { EndoSequence BC sealer } \\
\text { vs ProRoot MTA sealer }\end{array}$ & $17.58-8.24$ & 14.00 & 0.38 \\
$\begin{array}{l}\text { EndoREZ sealer vs } \\
\text { ProRoot MTA sealer }\end{array}$ & $20.03-9.88$ & 37.50 & 0.06 \\
\hline
\end{tabular}

Table 4: Intergroup comparison at apical third

\begin{tabular}{llll}
\hline Inter groups & Mean rank & Mann-Whitney U test & p value \\
\hline $\begin{array}{l}\text { EndoSequence BC sealer } \\
\text { vs EndoREZ sealer }\end{array}$ & $24.18-8.30$ & 42.76 & 0.001 \\
$\begin{array}{l}\text { EndoSequence BC sealer } \\
\text { vs ProRoot MTA sealer }\end{array}$ & $19.58-8.96$ & 16.10 & 0.46 \\
$\begin{array}{l}\text { EndoREZ sealer vs Pro- } \\
\text { Root MTA sealer }\end{array}$ & $22.48-1.88$ & 40.88 & 0.001 \\
\hline
\end{tabular}


have been conflicting. ${ }^{8}$ In the existing study, SEM-a method of histological evaluation has been used to assess the root canal seal quality. Scanning Electron Microscope has greater resolution, improved interface magnification, and superior field depth, which has also been stated by Punithia and Shashikala. ${ }^{9}$

In this study, the highest marginal adaptation was displayed by EndoSequence BC sealer tracked by ProRoot MTA sealer and EndoREZ sealer. Similar findings have been reported by Zhou et al. ${ }^{10}$ who demonstrated that EndoSequence $B C$ sealers have reduced film thickness and improved flow. Additionally, Polineni et al. ${ }^{11}$ described that the sealers may penetrate the dentinal tubules due to alkaline nature of the bioceramic byproducts that denature the collagen fibers of dentin.

EndoSequence BC sealer is a nonaqueous premixed calcium phosphate silicate-based sealer distributed in carriers that are water-miscible and it becomes hard when comes in contact with moist root dentin. In this study, improved marginal adaptation was shown by EndoSequence BC sealer than the other sealers. Hegde and Arora ${ }^{12}$ and Pawar et al. ${ }^{13}$ found the hydrophilic sealers to demonstrate increased marginal adaptation and lesser apical micro leakage values. Candeiro et al. ${ }^{14}$ established adequate flow values which corresponds with their commendations of ISO 6786/2001.

In our study, EndoREZ sealer demonstrated relatively reduced marginal adaptation. EndoREZ is an UDMA resin-based sealer which has been shown to have hydrophilic characteristics and easy delivery system. This result is unlike those obtained by Mamootil and Messer ${ }^{15}$ who found a higher mean maximum adaptation of methacrylate resin-based sealer EndoREZ in their SEM based study. A similar SEM examination was performed by Tay et al. ${ }^{16}$ who found a better sealing ability by the EndoREZ sealer in the middle and coronal portions of the root canals.

The most important role of a root canal sealer is to enhance the adaptation of the obturation material to the canal walls and to seal irregularities, without which there would be increased chances of micro leakage and endodontic failures. An optimal root canal sealer should have reduced surface tension to permit improved penetration into irregularities, increased wettability to provide liquid tight seal and must be biocompatible. Insufficient filling of root canal space leads to approximately $60 \%$ of endodontic failures. This paved the way for developing novel endodontic substances and obturation techniques. ${ }^{17}$

After obturation, the respective sealer samples were kept in humidor to confirm total setting of sealers for 1 week and reduce the sealer's final setting time. In the same way, Nair et al. ${ }^{18}$ kept the specimens in humidor for 7 days to permit setting of the sealers. Loushine et al. ${ }^{19}$ showed EndoSequence $B C$ to form a more permeable matrix and have increased initial setting time ( 180 hours) and reduced micro hardness of the set cement with the increase in quantity of water in the course of the setting of sealer.

In a study by Nair et al. ${ }^{18}$ the sealing capability of endo sequence and ProRoot MTA was compared using a model based on bacterial leakage and the groups did not show significant difference.

However, the results of current study do not agree with Hirschberg et al. ${ }^{20}$ who found that the samples in the EndoSequence group leaked significantly more than the samples in the MTA group.

In the current study the teeth samples were cut longitudinally and during this the gutta-percha may get withdrawn from the canals thus modifying the results. Also, the single-rooted teeth that were obturated under ideal conditions in in vitro state were used in this study. These above-mentioned factors can be considered as demerits of our study. It is difficult to clinically reproduce the thin sealer layer caused by obturation. Comparative clinical studies that evaluate the importance of adaptation of root canal sealer to canal walls using with proven adhesion properties are needed in the future.

\section{Conclusion}

The present study concluded that significant and better sealing ability and marginal adaptation was demonstrated by EndoSequence BC (bioceramic sealer) when compared to ProRoot MTA sealer (MTA-based sealer) and EndoREZ sealer (resin-based sealer).

\section{References}

1. Pathak S. Comparative Evaluation of Sealing Ability of Root End Filling Materials: An In-Vitro Study. Int J Dent Med Res 2015;1(5):48-52.

2. Ehsani M, Dehghani A, Abesi F, et al. Evaluation of apical microleakage of different endodontic sealers in the presence and absence of moisture. J Dent Res Dent Clin Dent Prospects 2014;8(3):125-129.

3. Kim YK, Grandini S, Ames JM, et al. Critical review on methacrylate resin-based root canal sealers. J Endod 2010;36(3):383-399. DOI: 10.1016/j.joen.2009.10.023.

4. Wu MK, De Gee AJ, Wesselink PR. Effect of tubule orientation in the cavity wall on the seal of dental filling materials: an in vitro study. Int Endod J 1998;31(5):326-332. DOI: 10.1046/j.1365-2591.1998.00144.x.

5. Chen H, Zhao X, Qiu Y, et al. The tubular penetration depth and adaption of four sealers: a scanning electron microscopic study. Biomed Res Int 2017;2017:1-8.

6. Tyagi S, Mishra P, Tyagi P. Evolution of root canal sealers: an insight story. Eur J Gen Dent 2013;2(3):199-218. DOI: 10.4103/22789626.115976.

7. Wu MK, Wesselink PR. Endodontic leakage studies reconsidered. Part I. Methodology, application and relevance. Int Endod J 1993;26(1): 37-43. DOI: 10.1111/j.1365-2591.1993.tb00540.x.

8. Ferreira R, Bombana AC, Sayeg IJ. In vitro analysis of the penetration of methylene blue dye in human radicular dentin using different methods of impregnation. Aust Endod J 2008;34(3):110-114. DOI: 10.1111/j.1747-4477.2007.00107.x.

9. Punithia PG, Shashikala K. Evaluation of the adaptation of resin based sealers epiphany, AH plus and $\mathrm{AH} 26$ to the root canal dentin by scanning electron microscope. Indian J Stomatol 2011;2(4): 207-211.

10. Zhou HM, Shen $Y$, Zheng W, et al. Physical properties of 5 root canal sealers. J Endod 2013;39(10):1281-1286. DOI: 10.1016/ j.joen.2013.06.012.

11. Polineni S, Bolla N, Mandava P, et al. Marginal adaptation of newer root canal sealers to dentin: a SEM study. J Conserv Dent 2016;19(4): 360-363. DOI: 10.4103/0972-0707.186453.

12. Hegde V, Arora S. Sealing ability of three hydrophilic single-cone obturation systems: An in vitro glucose leakage study. Contemp Clin Dent 2015;6(Suppl 1):S86-S89. DOI: 10.4103/0976-237X.152953.

13. Pawar SS, Pujar MA, Makandar SD. Evaluation of the apical sealing ability [26] of bioceramic sealer, AH plus \& epiphany: An in vitro study. J Conserv Dent 2014;17(6):579-582. DOI: 10.4103/0972-0707. 144609.

14. Candeiro GT, Correia FC, Duarte MA, et al. Evaluation of radiopacity, ph, release of calcium ions, and flow of a bioceramic root canal sealer. J Endod 2012;38(6):842-845. DOI: 10.1016/j.joen.2012.02.029.

15. Mamootil K, Messer H. Penetration of dentinal tubules by endodontic sealer cements in extracted teeth and in vivo. Int Endod J 2007;40(11):873-881. DOI: 10.1111/j.1365-2591.2007.01307.x.

16. Tay F, Loushine R, Monticelli $F$, et al. Effectiveness of resin-coated guttapercha cones and a dual-cured, hydrophilic methacrylate resinbased sealer in obturating root canals. J Endod 2005;31(9):659-664. DOI: 10.1097/01.don.0000171942.69081.53. 
17. Muliyar S, Shameem KA, Thankachan RP, et al. Microleakage in endodontics. J Int Oral Health 2014;6(6):99-104.

18. Nair U, Ghattas S, Saber M, et al. A comparative evaluation of the sealing ability of 2 root-end filling materials: an in vitro leakage study using enterococcus faecalis. Oral Surg Oral Med Oral pathol Oral Radiol Endod 2011;112(2):e74-e77. DOI: 10.1016/j.tripleo.2011.01.030.
19. Loushine BA, Bryan TE, Looney SW, et al. Setting properties and cytotoxicity evaluation of a premixed bioceramic root canal sealer. J Endod 2011;37(5):673-677. DOI: 10.1016/j.joen.2011.01.003.

20. Hirschberg CS, Patel NS, Patel LM, et al. Comparison of sealing ability of MTA and EndoSequence bioceramic root repair material: a bacterial leakage study. Quintessence Int 2013;44(5):e157-e162. 